\title{
Perspective
}

\section{Prevention from Corona Virus while performing operation in OT by innovating indigenous simple face mask shield}

\author{
Sudhir Singh ${ }^{1, *}$ \\ ${ }^{1}$ Dept. of Plastic Surgery, Getwell Hospital, Varanasi, Uttar Pradesh, India
}

\section{A R T I C L E I N F O}

\section{Article history:}

Received 07-04-2020

Accepted 10-04-2020

Available online 15-06-2020

\section{Keywords:}

Corona

Mask shield

N95

Plastic OHP A4 sheet

Surgical mask

\begin{abstract}
A B S T R A C T
There is crisis of availability of PPE and proper facemasks to get protected while operating patients irrespective of Corona virus infection in OT in our place during present time in March-April 2020. So necessity is mother of invention. I devised a method of indigenously creating face mask shield for OT purpose to tide over the crisis period till proper PPE kit and better shield masks are available to us as frontline COVID19 warriors in OT. It seems to be good indigenous method to cross over the present crisis of proper PPE for facial masks. It gives the wearer a welcome sense of security. It feels like I am behind a shield and that in itself can be reassuring to be protected from direct onslaught of Corona virus.
\end{abstract}

(C) 2020 Published by Innovative Publication. This is an open access article under the CC BY-NC license (https://creativecommons.org/licenses/by-nc/4.0/)

\section{Introduction}

Current WHO recommendations emphasize the importance of rational and appropriate use of all PPE, not only masks, which requires correct and rigorous behavior from health care workers, particularly in doing OT procedures. However in this peak time of COVID19 pandemic there is short supply of even proper PPE and even surgical masks. We had faced this here in Varanasi in this month of MarchApril 2020. So necessity is mother of invention. I devised a method of creating indigenous face mask shield for OT purpose to tide over the crisis period till proper PPE kit and better shield masks are available to us as frontline COVID19 warriors in OT. It seems to be good indigenous method to cross over the present crisis. It gives the wearer a welcome sense of security. It feels like I am behind a shield and that in itself can be reassuring to be protected from direct onslaught of coronavirus.

\section{Materials}

Materials are the following

\footnotetext{
* Corresponding author.

E-mail address: s.sulekha@gmail.com (S. Singh).
}

1. I prefer using any N-95 filtration with proper face fitting mask preferably with silver coating to further kill the viruses. If not then go for less efficient three layered surgical mask.

2. Transparent plastic A4 size color painting OHP sheets available in any book store

3. Punching hole appliance to punch hole on either side of plastic sheet in the middle of breath side about 1 to $2 \mathrm{~cm}$ inside for tying the string.

4. Two strings for tying purpose

5. Sanitizer to sanitize the sheet before using in OT

\section{Methods}

First two holes are punched about 1 to $2 \mathrm{~cm}$ inside at either side on middle of breath side of the transparent A4 size OHP plastic sheet(Figures 3 and 4). Two strings are tied individually on each hole(Figure 3 ). Then it is either sanitized with sanitizer or can be washed with soap water as desired by surgeon. During OT procedure the $\mathrm{N}-95$ mask is worn and we get ensured about its proper fitting on nose and mouth over face(Figure 2). Then this transparent sheet is worn infront over the mask and is tied 
with the help of fastened strings behind the head. It covers eyes, nose and mouth. Surgeon is now doubly protected from direct onslaught of virus droplets while operating the patient(Figure 1).

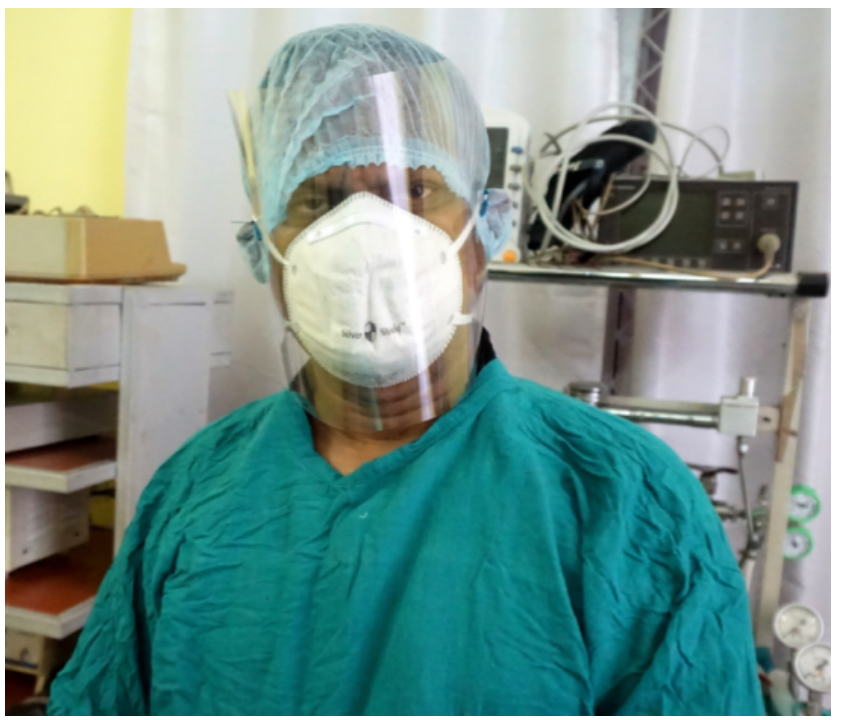

Fig. 1: In OT with face mask shield

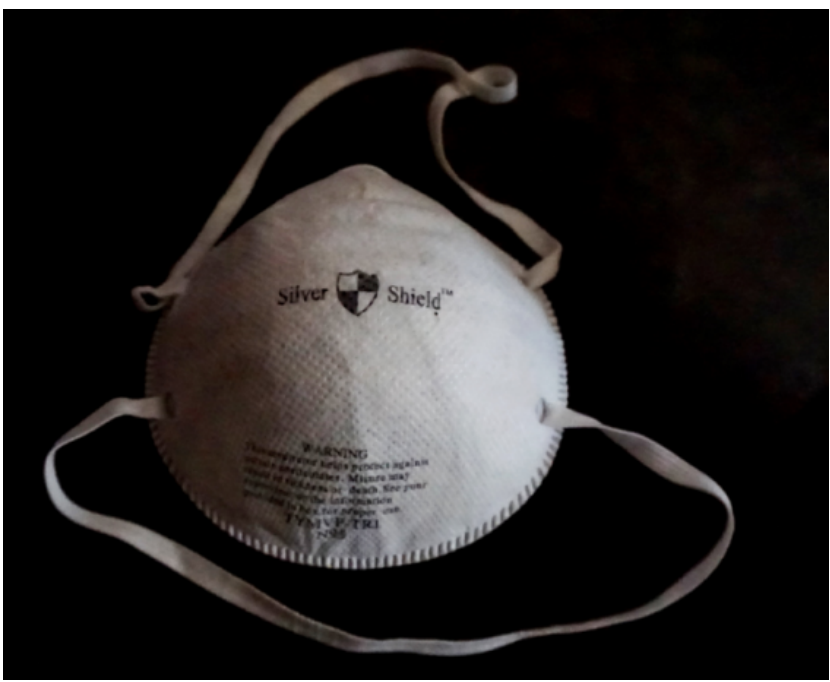

Fig. 2: N95 Mask

\section{Discussion}

There has been lot of confusion about the use of surgical three layered or N-95 silver coated filter masks for OT purpose during operation of patients in current COVID19 time irrespective of infection or not. There is no cure for the infection as of present. So the golden rule of prevention of oneself specially in OT with proper PPE or with at least using proper mask is a must. ${ }^{1,2}$

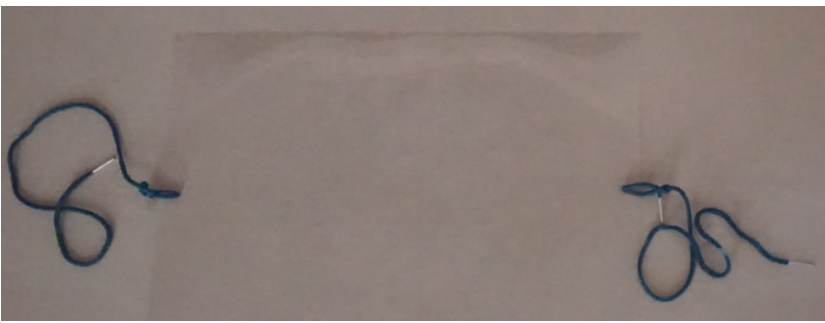

Fig. 3: Plastic sheet with strings to be used as face mask shield

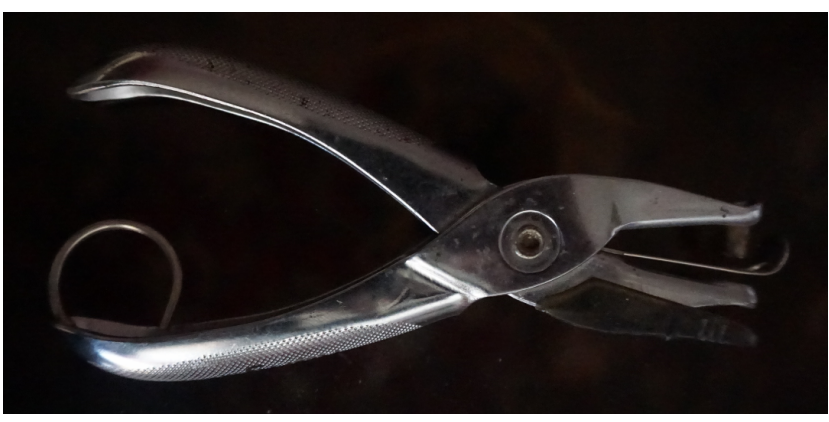

Fig. 4: Punching equipment

SARS-CoV-2 belongs to the beta-corona virus category. It has round or elliptic and often pleomorphic form, and a diameter of approximately 60-140 $\mathrm{nm}$. These viruses can be effectively inactivated by lipid solvents including ether $(75 \%)$, ethanol, chlorine-containing disinfectant, peroxyacetic acid, etc. It is being established that virus not only spread by droplets but also by aerosol created specially during intubating and extubating of endotracheal tubes in OT room while treating the surgical patient. Respiratory droplets sprayed during activities such as coughing or speaking, range from about 0.1 micron to few hundred microns. For comparison the average human hair has a diameter of about 75 microns. Droplets larger than 10 microns tend to get produced during coughing, sneezing or speaking loudly and can carry larger number of viruses. It has been also said that during forceful coughing the spread distance can go up to twenty four feet. They tend to get lodged in the upper part of respiratory tract. Aerosols contain droplets of smaller than 10 microns and can float in the air and travel deep into the respiratory passages of person standing nearby. Usually the droplets don't go beyond six feet. Airborne transmission is different from droplet transmission as it refers to presence of viruses with in droplet nuclei less than five micron in diameter which can remain in air for long time even for three to four hours and can be transmitted to distance greater than six feet. It is more common in OT procedures like endotracheal intubation, bronchoscopy, open suctioning, administration of nebulized treatment, and manual ventilation before intubation, turning patient to prone position, disconnecting the patient from ventilator, tracheostomy, noninvasive positive pressure 
ventilation and cardiopulmonary resuscitation. We have to consider it as airborne transmission irrespective of any body's denial unless proved otherwise. ${ }^{3}$ Till then erring on side of every patient as suspicious COVID19 and arming ourselves with protecting tools is the best preventive measure. ${ }^{1}$

The three layered surgical mask is not so good because its use in stopping 0.02 to 1 micron is only 70 to 80 percent but N -95 mask gives more than 99 percent results. ${ }^{4-6}$ The cotton cloth mask in OT is useless which cannot stop this virus entry. However N-95 mask scores over surgical three layered mask in terms of close facial fit and efficient filteration of airborne particles. If this mask is coated with silver it gives further impetus to kill microbes and viruses. It blocks more than 95 percent of 0.3 micron particles but does not completely eliminate the risk of illness or death. So the need of transparent plastic or glass sheet as a further shield to cover the whole of face over the mask give lot of advantage in preventing infection through mouth, nose and conjunctiva of eyes. ${ }^{5,6}$ Snugly fitting eye glass forming a protective shield around eyes, if required can be worn behind the transparent plastic shield sheet. This further prevents aerosols from entering under or around the goggles.

Most of surgeons like us in this part of our country are facing acute shortage of supply of PPE and even the three layered surgical OT masks during these months of MarchApril 2020. Most of the world's face masks are made in China and Taiwan which themselves are unable to meet their own country demand in this period of COVID19 infection. So necessity is mother of invention. I devised a method of creating indigenously using mask with transparent plastic face mask shield for OT purpose to tide over the crisis period till proper PPE kit and better shield masks are available to us as frontline COVID19 warriors in OT (Figures 1, 2, 3 and 4).

\section{Results and Conclusions}

It seems to be good indigenous method to cross over the present crisis of proper PPE for facial masks. While
COVID-19 has been suggested to have a lower case fatality rate $(2.5 \%)$ than SARS $(9.6 \%)$, MERS $(34.4 \%)$, or H1N1 $(17.4 \%)$, the extent of spread means that the death toll is significant. Frontline healthcare workers are at high risk of becoming infected, and are also at risk of spreading infection.

\section{Acknowledgement}

None.

\section{Conflict of interest}

None.

\section{References}

1. Cdc. CDC. 2003. Cluster of severe acute respiratory syndrome cases among protected healthcare workers-Toronto, Canada. Morb Mortal Weekly Rep. 2003;52(19):433-6.

2. Ong SW, Tan YK, Chia PY, Lee TH, Ng OT, Wong MS, et al. Air, surface environmental, and personal protective equipment contamination by severe acute respiratory syndrome coronavirus 2 (SARS-CoV-2) from a symptomatic patient. JAMA. 2020;323(16):1610-12.

3. van Doremalen N, Bushmaker T, Morris DH, Holbrook MG, Gamble A, Williamson BN, et al. Aerosol and Surface Stability of SARS-CoV-2 as Compared with SARS-CoV-1. N Engl J Med. 2020;382:1564-7.

4. ASTM. Standard Test Method for Determining the Initial Efficiency of Materials Used in Medical Face Masks to Penetration by Particulates Using Latex Spheres. West Conshohocken: ASTM; 2003.

5. Belkin NL. The evolution of the surgical mask: Filtering efficiency versus effectiveness. Infect Control Hospital Epidemiol. 1997;18(1):49-57.

6. Ha'eri G, Wiley A. The efficacy of standard surgical face masks: An investigation using "tracer particles. Clin Orthop Related Res. 1980;148:160-2

\section{Author biography}

Sudhir Singh Hon. IMA Professor and Senior Consultant

Cite this article: Singh S. Prevention from Corona Virus while performing operation in OT by innovating indigenous simple face mask shield. IP Indian J Immunol Respir Med 2020;5(2):132-134. 